\title{
¿PUEDE LA LEGISLACIÓN CUALIFICADA SOCAVAR LA DEMOCRACIA? EL CASO DE HUNGRÍA ${ }^{1}$
}

\author{
BOLDIZSÁR SZENTGÁLI TÓTH \\ Investigador del Instituto de Estudios Legales de Hungría
}

\section{SUMARIO}

I. Consideraciones preliminares. II. La construcción y recepción de la legislación cualificada. III. La legislación cualificada en Hungría. IV. Conclusiones.

El presente estudio pretende analizar las denominadas Leyes Cardinales en Hungría ${ }^{2}$, intentando arrojar luz sobre el concepto especialmente para conceptualizar su rol histórico y su función en el ordenamiento jurídico húngaro, a lo largo de la transición democrática, y también en la actualidad. Se hará especial hincapié en el impacto que tienen aquéllas en situaciones de mayoría parlamentaria cualificada.

\section{CONSIDERACIONES PRELIMINARES}

El término «legislación cualificada» debe ser definido claramente. Los diferentes sistemas jurídicos suelen conceptuar de forma diferente lo que entienden por esa «legislación cualificada», aunque se detectan ciertos puntos en común. Así, la ley cualificada es una subcategoría de leyes, prescritas constitucionalmente, que se reservan para las materias más cruciales, que están garantizadas por cautelas procedimentales especialmente reforzadas que no existen en el caso de la legislación ordinaria ${ }^{3}$.

1 Traducción de I. ÁLVAREZ RODRÍGUEZ (Profesor de Derecho Constitucional de la Universidad de Valladolid, Campus de Segovia).

2 El equivalente español son las Leyes Orgánicas.

3 J.P. CAMBY, «Quarante ans de lois organiques», Revue de droit publique, 1998/5-6, pp. 1686-1698.; A. JAKAB - E. SZILÁGYI, «Sarkalatos törvények a magyar jogrendszerben», Új Magyar Közigazgatás, 2014/3, pp. 96-110; P. Avril - J.GicQuel, Droit parlamentaire, Dalloz, Paris, 2014, pp. 267-307. 
El modelo húngaro de este tipo de normas es la Ley Cardinal. El equivalente en España es la Ley Orgánica ${ }^{4}$.

Después de realizar un repaso internacional a esta noción, y de haber señalado algunas consideraciones introductorias, me detendré sobre tres aspectos. En primer lugar, el trasfondo histórico. En segundo lugar, en el foco, en el objeto, de estas leyes cardinales. En tercer lugar, en su carácter legal (jurídico, normativo). Sobre cada uno de los aspectos se comparará el desarrollo húngaro y el desarrollo español, en aras de demostrar que este tipo de normas pueden suponer un factor de riesgo para la democracia húngara, a la vez que se expone cómo las leyes orgánicas no lo son para la democracia española.

Lo cierto y verdad es que los diferentes ordenamientos jurídicos emplean multitud de expresiones para referirse al mismo fenómeno que tratamos aquí de la legislación cualificada. Y aunque la terminología no es el factor decisivo para el análisis de fondo, en esta concreta cuestión merece la pena tenerlo en cuenta, máxime teniendo en cuenta que los matices terminológicos exhiben las diferentes funciones de este concepto legal: constitucional, político, histórico, y el basado en la soberanía; todos ellos serán abordados a continuación.

\section{LA CONSTRUCCIÓN Y RECEPCIÓN DE LA LEGISLACIÓN CUALIFICADA}

El término «ley orgánica» se emplea en la Constitución de Francia ${ }^{5}$, España $^{6}$, Rumania, y Moldavia. Este enfoque tiene que ver con el Derecho Constitucional, aunque ese carácter cuasi-constitucional no se predique de las mismas ${ }^{7}$. La categoría de «leyes con fuerza constitucional» se introdujo en Hungría durante la transición a la democracia, y tenían el mismo rango que los artículos de la propia Constitución ${ }^{8}$. La forma de «leyes adoptadas por mayoría de dos tercios» también se aplicó durante dos décadas en el país magiar (desde 1990 hasta 2011). Aquí importa la vertiente política: en lugar de mayoría simple, un amplio consenso se hacía necesario para crear o enmendar las leyes cualificadas.

La Ley Fundamental húngara estableció, o reinstauró, un nuevo concepto normativo, la ley cardinal ${ }^{9}$, que tiene la misma lógica que las originarias, esas

4 B. SzentGáli-Tóth, A minösített többséggel elfogadott törvények múltja, jelene és jövöje a magyar jogrendszerben, Parliaments Practicum 2011-2012, (ed. István Soltész) Parliamentary Methodology Office, Budapest, 2014, pp. 71-101.

5 Artículo 46 de la Constitución Francesa. [04.10.1958].

6 Art. 81.1 de la Constitución Española. [27.12.1978].

7 Décision du CC, n 84-177 DC du 30 aout 1984; N 66-28, DC du 8 juilet 1966 (Rec., p. 15).

8 G. KILÉNYI, «Az alkotmányozási folyamat és a kétharmados törvények», Jogtudományi Szemle, $1994 / 5$, pp. 201-209.

9 Art. T. (4) de la Ley Fundamental de Hungría [25.04.2011]. 
«leyes adoptadas por dos tercios de la mayoría». Este gesto simbólico hacía más visible la retórica historicista de la nueva Constitución ${ }^{10}$.

Francia, España, y Hungría representan tres modelos que comprenden algún tipo de ley que exige mayoría cualificada. De todos modos, el asunto de esa legislación cualifica concierne no sólo a esos tres países, pero también a otros sistemas constitucionales a lo largo y ancho del mundo.

Independientemente de que algunos elementos del desarrollo constitucional Inglés han sido muy próximos a la idea de la legislación de este tipo ${ }^{11}$, la historia moderna de la legislación cualificada se remonta al año 1958, cuando se aprueba la Constitución de la V República ${ }^{12}$. Después de la descolonización de África, varios países de la zona han recogido la idea de la ley orgánica en su diseño constitucional $^{13}$, en concreto hasta 21 Estados con apoyo expreso en esa figura, como Argelia $^{14}$, Senegal ${ }^{15}$ o Túnez ${ }^{16}$, entre otros ${ }^{17}$.

La segunda ola de llegada de este tipo de leyes sucedió al hilo de la caída de las dictaduras en España y en Portugal ${ }^{18}$, con su introducción en las dos Constituciones $^{19}$, respectivamente $y$, posteriormente, el ejemplo fue seguido por un considerable número de países latinoamericanos, como por ejemplo Ecuador $^{20}$, o Venezuela $^{21}$, dentro de un nutrido y relevante grupo $^{22}$.

10 H. KÜPPER, «A KÉTHARMADOS/SARKALATOS TÖRVÉNYEK JELENSÉGE A MAGYAR JOGRENDSZERBEN》, MTA Law Working Papers, 2014/46, pp. $2-5$.

11 P. LEYLAND, The constitution of the United Kingdom: a contextual analysis, Hart Publishing, Oxford, Portland, 2012, pp. 25-42.

12 Art. 46 de la Constitución Francesa.

13 R. David, Les grands systemes de droit contemporains, Dalloz, Paris, 1964, pp. 630.

14 Art. 123 de la Constitución de Argelia. [15.05.1996].

15 Art. 78 de la Constitución de Senegal. [07.01.2001].

16 Art. 65 de la Constitución de Túnez. [26.01.2014].

17 Art. 166 (2) b) y art. 169 (2) de la Constitución de Angola [21.01.2010]; art. 97 de la Constitución de Benín [02.12.1990]; art. 155 de la Constitución de Burkina Faso [02.06.1991]; art. 127 de la Constitución de Chad [1996]; art. 66 de la Constitución de Djibouti [1992]; art. 104 de la Constitución de Equatorial Guinea [1991]; art. 71 de la Constitución de Ivory Coast [08.11.2016]; art. 60 de la Constitución de Gabón [1991]; art. 83 de la Constitución de Guinea [07.05.2010]; art. 124 de la Constitución de República Democrática del Congo [18.02.2006]; art. 125 de la Constitución de la República del Congo [2001]; art. 52. 70.73. 77. 80. 85. 87. 89. 92. 93.99. 101. 102. 103. y 105. de la Constitución de la República Centroafricana [27.12.2004]; art. 88 y 89 de la Constitución de Madagascar [14.11.2010]; art. 85 y 86 de la Constitución de Marruecos [01.07.2011]; art. 67. de la Constitución de Mauritania [12.07.1991]; art.131. de la Constitución de Nigeria [31.10.2010]; art. 92. de la Constitución de Togo [14.10.1992]; art. 73. (3) y art. 86. (2) b) de la Constitución de Islas de Islas Verdes [1980].

18 Art. 81.1 de la Constitución de España [07.12.1978]; art. 136. (3) de la Constitución de Portugal [02.04.1976].

19 D Conversi, «The Smooth Transition», National Identities, Vol. 4, 2002/3, pp. 223-244.

20 Art. 133 de la Constitución de Ecuador [28.09.2008].

21 Art. 203 de la Constitución de Venezuela [20.12.1999].

22 Art. 63 de la Constitución de Chile [21.10.1980]; art. 112 de la Constitución la República Dominicana [13.06.2015]; art. 151 de la Constitución de Colombia [04.07.1991]; art. 164 de la Constitución de Panamá [1972]; art. 106 de la Constitución de Perú [31.12.1993]; Ricardo Sepúlveda, Las leyes orgánicas constitucionales, UNAM, México, 2006, pp. 100-112. 
Finalmente, hubo una tercera ola, después de la caída los regímenes comunistas de Centro-Europa, con la llegada de la institución de la legislación cualificada en los sistemas constitucionales de Hungría, Rumania ${ }^{23}$, y Moldavia ${ }^{24}$. También algunas ex Repúblicas Soviéticas implementaron instituciones similares, pero las disposiciones constitucionales relevantes sobre el particular fueron posteriormente revocadas.

\section{LA LEGISLACIÓN CUALIFICADA EN HUNGRÍA}

Por un lado, la inspiración histórica fue un factor de importancia en la recepción y desarrollo de la legislación cualificada en Hungría. Así, el concepto de ley cardinal proviene del medievo, y era parte integral de la constitución histórica húngara hasta el final de la Segunda Guerra Mundial ${ }^{25}$. Intentando resistir a los esfuerzos absolutistas de la dinastía de los Habsburgo, se adoptó una lista más o menos exhaustiva de leyes cardinales, marco legal que sirvió para que se hablara de «la Constitución histórica del país» ${ }^{26}$. Dicha abstracción estaba claramente influenciada por el desarrollo constitucional en Inglaterra ${ }^{27}$.

Por otro lado, las leyes cualificadas modernas en Hungría se crearon para asegurar la pacífica y continuada transición del sistema político y para prevenir la posibilidad de una nueva dictadura. Algunos autores han defendido la influencia francesa en este planteamiento ${ }^{28}$, mientras que otros rechazan la migración de la idea constitucional ${ }^{29}$, sosteniendo que el factor primario se encuentra en las tradiciones nacionales ${ }^{30}$.

Debido a razones políticas Hungría ha desarrollado al menos tres conceptos diferentes de legislación cualificada en el marco de tres décadas. En el momento de las negociaciones de la mesa redonda (verano y otoño de 1989), tanto el gobierno comunista como la oposición querían reducir el miedo al incierto futuro con la ayuda de una mayoría cualificada. Esta solución aseguraría la participación de todos los partidos políticos relevantes en las decisiones venideras acerca de

23 Art. 73 (3) de la Constitución de Rumanía. [08.12.1991].

24 Art. 61 (2), art. 63 (1) y (3), art. 70 (2), art. 72 ((3) y (4), art. 74 (1), art. 78 (2), art. 80 (3), art. 97 art. 99 (2), art. 108 (2), art. 111 (1) y (2), art. 115 (4), art. 133 (5) de la Constitución de Moldova. [29.07.1994].

25 I. SzÉCHenYi, A sarkalatos törvények és a Magyar közjog fejlödése 1848-ig, Eggenberger Ferdinánd Akad. Press, Pest, 1864, p. 168.

26 J. HajNóczy, «Magyarország Országgyűléséről.», 1791, Hajnóczy József közjogi-politikai munkái, Akadémiai Kiadó, Budapest, 1958, pp. 236-240.

27 I. KukORelli (ed.), Alkotmánytan, Osiris, Budapest, 2002, p. 31.

28 L. TrócsánYI, «Alaptanok», L. Trócsányi - B. Schanda, Bevezetés az alkotmányjogba. Az Alaptörvény és Magyarország alkotmányos intézményei, Hvgorac, Budapest, 2014, p. 55.

29 «Regarding the general tendencies of circulation of constitutional ideas», S. CHOudHry, (ed.) The Migration of Constitutional Ideas, Cambridge, Cambridge University Press, 2006, pp. 1-35.

30 A. JAKAB, «A kétharmados törvények egyes problémái az Alkotmányban», Új Magyar Közigazgatás, 2009/10-11, p. 38. 
cuestiones tan sensibles como los derechos fundamentales y el marco institucional. Lo que es mas, la nueva configuración política hubiera requerido diversas enmiendas constitucionales, pero sólo algunas de las mismas estaban listas y operando en el otoño de aquel año. El comienzo de las leyes con fuerza constitucional $^{31}$ con una extensión muy amplia ${ }^{32}$, permitió a los llamados a redactar las nuevas normas la posibilidad de adoptar nuevas reglas cuasi constitucionales durante las sesiones del Parlamento. Así, la Constitución fue enmendada sobre la base de un compromiso gobierno-oposición ${ }^{33}$, limitando el ámbito de la mayoría cualificada a una lista tasada de materias. En lugar de exigir el consentimiento de dos tercios de todos los diputados, se exigió esos dos tercios de los presentes para buena parte de supuestos ${ }^{34}$.

Esta terminología se revocó en 2012, por la Ley Fundamental de Hungría, que resucitó de nuevo a la ley cardinal, pero con contenidos revisados ${ }^{35}$. El ámbito de acción también fue modificado: los derechos fundamentales dejaron de ser materias cualificadas, reforzando el marco institucional. La fuente de la mayoría cualificada también muta: añadidamente al background constitucional, se une una cláusula cardinal a cada ley, con previsiones cardinales ${ }^{36}$. Estas cláusulas enumeran explícitamente qué cuáles quedan dentro del ámbito competencial de lo cardinal y cuáles no. Además, estas cláusulas quedan sometidas a revisión constitucional $^{37}$.

A la luz del desarrollo subsiguiente en Hungría, un fenómeno añadido es el del reducido rol de la mayoría cualificada como salvaguarda. Desde que el sector gubernamental tuvo una mayoría de dos tercios en el Parlamento Húngaro entre 2010 y 2015, se han podido modificar unilateralmente leyes cardinales, incluso previsiones constitucionales que caían dentro de los dominios cardinales. La mayoría parlamentaria cualificada emplea esta oportunidad en un círculo amplio, y la demostración más palpable es la adopción de la nueva Ley Fundamental. Por poner otro ejemplo, el ámbito de acción de la legislación cualificada se ha modificado en dos ocasiones con motivo de la organización de las Iglesias, sobre la base de criterios más bien políticos ${ }^{38}$.

31 Act XXXI. de 1989 art. 8.

32 KILÉNYI, 1994.

33 A. Bozóki, (ed.), The Roundtable Talks of 1989: The Genesis of Hungarian Democracy, Central European University Press, Budapest, 1999, p. 2478; J. Elster - C. Offe - Ulrich Preuss, Constitutional Politics in Eastern Europe, Cambridge, Cambridge University Press, 1998, pp. 63-108.

34 Act. XL. of 1990.

35 Art. T) de la Ley Fundamental de Hungría.

36 D- Barna - B- Szentgáli-Tóth, «Stabilitás vagy Parlamentarizmus? - A sarkalatos törvényekkel kapcsolatos egyes jogalkotási problémák.» Ars Boni Law Review, 14.02.2013, www.arsboni.hu/barnaszentg. html.

37 Decisión Nr. 17/2013. (VI. 26.) AB, ABH 2013, 583; decisión Nr. 16/2015. (VI. 5.) AB, ABH 2015

38 Art. 4 de la Cuarta Enmienda de la Ley Fundamental de Hungría; art. 1. de la Cuarta Enmienda de la Ley Fundamental de Hungría. 
Para comparar, valga el caso español, donde las leyes orgánicas se regularon mediante la Constitución de 1978, después de la caída del régimen franquista, como parte de la transición democrática del país. Dejando de lado la clara influencia francesa, el background histórico del proceso constituyente fue completamente diferente que el del caso galo. España tenía falta de tradición democrática, las dos Repúblicas previas habían tenido una vida muy corta, fracasando en crear estabilidad y mecanismos eficientes que prevengan aspiraciones autoritarias ${ }^{39}$. Aun es más, un reseñable grado de incertidumbre rodeó la transición: inicialmente fue muy cuestionada, sobre todo por las dudas de si el nuevo Rey se decantaría por el proceso democrático o mantendría algún tipo de dictadura. Los padres constituyentes buscaron soluciones, y las encontraron en crear mecanismos para que el propio sistema democrático consiguiera autodefenderse. De hecho, el principal propósito de aquéllos era establecer «cortafuegos democráticos», y la ley orgánica era uno de ellos. Dado lo numeroso de los partidos políticos ${ }^{40}$ y de las identidades regionales ${ }^{41}$, la vida política española estaba muy fragmentada, por ello era necesario y esencial un amplio consenso para crear la nueva estructura y mantener la integridad del país ${ }^{42}$. Estas preocupaciones explican el relativamente amplio círculo de la legislación orgánica española ${ }^{43}$.

Hungría nos ofrece un caso especial desde la perspectiva de la legislación cualificada: el enfoque de la mayoría cualificada ha sido modificado continuamente desde 1989. Las leyes con fuerza constitucional cubren todas las normas, que afectan a derechos fundamentales y demás libertades ${ }^{44}$, y fue extendida también a un amplísimo catálogo de campos institucionales. Después del compromiso entre gobierno y oposición en la primavera de 1990, se suprimió el carácter abierto de la enumeración de las materias cualificadas, y en lugar de la frase «todas las normas que afectan a los derechos y libertades fundamentales», se introduce un listado cerrado de los mismos, protegidos por mayoría de dos tercios, ahora para aproximadamente treinta materias.

Por ello el desarrollo húngaro muestra otra característica, al reconsiderarse el rol de las leyes cualificadas en el campo de los derechos fundamentales. Después de 1990, las funciones institucionales de protección de las leyes cualificadas fueron señaladas por el Tribunal Constitucional ${ }^{45}$, quien empleó el marco de referencia del contenido esencial para desarrollar el ámbito de la mayoría cualificada;

39 V. Ferreres Comella, «The Framing of the Spanish Constitution», V. Ferreres Comella, The Constitution of Spain: A Contextual Analysis, Bloomsbury Publishing PLC, Oxford, 2013, pp. 4-34.

40 A. Bonime-Blanc, «Constitution Making and Democratization. The Spanish Paradigm», in Laurel E. Miller - Louis Aucoin (ed.), Framing the State in Times of Transition. Case Studies in Constitution Making, USIP Press, Washington, 2010, pp. 417-432.

41 Conversi, 2002, pp. 223-244.

42 Conversi, 2002, p. 230.

43 Troper 2012, p. 344.

44 Art. 8 (2) de la act XXXI. de 1989.

45 Decisión Nr. 14/B/2002 AB, ABH 2003, 1476. 
esto es, la limitación de los derechos fundamentales debía hacerse siguiendo una mayoría cualificada ${ }^{46}$. Por poner un ejemplo, la limitación del derecho a la libertad religiosa es una materia de derechos fundamentales, mientras que la organización de las Iglesias queda cubierta por el manto institucional. El Tribunal Constitucional distinguió también, dentro del mismo texto legal, entre las provisiones ordinarias, y las previsiones cualificadas. Por ejemplo, sólo determinadas competencias de las fuerzas del orden caen bajo la protección de la mayoría cualificada ${ }^{47}$. Aun es más, el Tribunal Constitucional dejó claro que no todas las competencias de las instituciones quedan reguladas por las leyes cualificadas ${ }^{48}$. Durante las siguientes dos décadas el ámbito de acción de estas fue ampliado por enmiendas constitucionales: algunas cuestiones relacionadas con el estatus de los miembros del Poder Judicial, así como las reglas procedimentales-electorales se reconocieron como materias cualificadas ${ }^{49}$. La otra inspiración para extender el foco de estas leyes fue el refuerzo de la cooperación internacional y el acceso a la Unión Europea: la limitación de la soberanía de Hungría también se incorporó al acervo cualificado $^{50}$.

La elaboración de la Ley Fundamental en 2011 presentó nuevas tendencias. Primero, como se ha señalado antes, la relación entre derechos fundamentales y ley cualificada ha sido prácticamente abandonada. Se pensó que dada la vigilancia y control realizada por los organismos internacionales pertinentes, y ante la estabilidad de la democracia húngara, la mayoría cualificada no era el lugar adecuado para los derechos fundamentales ${ }^{51}$. A cambio, el rol de la mayoría cualificada se ha reforzado en el aspecto institucional, estableciendo autoridades independientes $^{52}$ y ampliando el número de instituciones afectadas. Esta tendencia se asemeja a la francesa, pero su desarrollo superó con mucho la organización estatal: diversas materias que hasta la fecha eran puramente políticas entraron dentro del radio de la mayoría cualificada, como la protección de las familias ${ }^{53}$, y las previsiones básicas de la imposición tributaria y del sistema de pensiones ${ }^{54}$. Aun es más, la Cuarta Enmienda a la Ley Fundamental extendió más allá la lista, incluyendo «los campos y los bosques» ${ }^{55}$. La inclusión de estas materias entra en conflicto con la función original del concepto de ley orgánica: no promueve la estabilidad, pero

46 Decision Nr. 4/1993. (II. 12.) AB, ABH 1993, 48.

47 Decisión Nr. 1/1999. (II. 24.) AB, ABH 1999, 25.

48 Decisión Nr. 26/1992. (IV. 30.) AB, ABH 1992, 135; decisión Nr. 1/1999. (II. 24.) AB, ABH $1999,25$.

49 Act XCVIII. of 1997.

50 Act XLI. of 2002.

51 Elemér BALOGH, Változások a magyar alkotmányjogban. Tanulmányok az Alaptörvényröl, FÁMA ZRT. National Press for Public Services and TanBooks, 2012, p. 53-79.

52 Art. 23 de la Ley Fundamental de Hungría.

53 Art. L) de la Ley Fundamental de Hungría.

54 Art. 40 de la Ley Fundamental de Hungría.

55 Art. P) (2) de la Ley Fundamental de Hungría. 
impone un límite muy severo, muy duro, en el margen de acción de futuros gobiernos. Los gobiernos que vengan tendrán serias dificultades para modificar el sistema de impuestos y/o el de pensiones. Y aunque se podría argumentar que la regulación de estas materias afecta directamente a los derechos fundamentales, esta lógica obligaría a considerar un círculo realmente extenso de leyes dentro de esa mayoría cualificada.

El caso de España es diferente. Un artículo específico de la Constitución establece las dos principales áreas de la ley orgánica: los Estatutos de Autonomía y los derechos y libertades fundamentales ${ }^{56}$. Además, otros tantos preceptos establecen que será la ley orgánica la que regule diversos aspectos institucionales, tales como la organización de las Fuerzas Armadas ${ }^{57}$, la sucesión al trono ${ }^{58}$, el referéndum ${ }^{59}$, o la organización del Poder Judicial ${ }^{60}$, amén del funcionamiento y organización del Tribunal Constitucional ${ }^{61}$. Así, el ámbito competencial de la ley orgánica cubre dos campos, principalmente: los derechos fundamentales y aspectos cruciales de muchas instituciones, lo que viene a establecer una suerte de balance entre ambos $^{62}$. Una ley orgánica también ha sido implementada para dar cobertura a la entrada de España en la Unión Europea ${ }^{63}$, lo cual entra en consonancia con la exigencia constitucional de la necesidad de una ley orgánica cada vez que se limita la soberanía del Estado a favor de organizaciones internacionales ${ }^{64}$. Las «Leyes Orgánicas Fundamentales» son exclusivamente aquellas que se regulan en los artículos 15-29 de la Constitución Española ${ }^{65}$. Dada la amplitud de la regulación constitucional, la labor del Tribunal Constitucional es la de interpretar racionalmente el modelo ${ }^{66}$. Y en la misma se aprecia que lo realmente importante no es su carácter orgánico o el contenido esencial, sino el dominio constitucional reservado a la misma ${ }^{67}$. Si una ley ordinaria interviene en dichos dominios, será anulada por el Juez de la Constitución ${ }^{68}$.

Comentemos ahora la jurisprudencia húngara más relevante, de nuevo comparándola con la experiencia española. Más allá de la preocupación doctrinal ${ }^{69}$, el

56 Art. 81-1 de la Constitución Española.

57 Art. 8 de la Constitución Española

58 Art. 57. (5) de la Constitución Española.

59 Art. 93. de la Constitución Española.

60 Art. 122. (1) de la Constitución Española.

61 Art. 65 de la Constitución Española.

62 JCC no. 77/1985

63 J. Iliopoulos-Strangas, Cours supremes nationales et cours européennes: concurrence ou collaboration? In memoriam Louis Favoreu, Bruylant, Bruxelles, 2007, p. 153.

64 Art. 93.1 de la Constitución Española.

65 Art. 104.1 de la Constitución Española.

66 SJCC 76/1983, 5 August, LC 2; 160/1987, 27 October LC 2).

67 Francisco Sosa WAGNer, «Aproximación al tema de las leyes orgánicas», Revista española de derecho administrativo, No. 21, 1979, pp. 199-204.

68 JCC no. $236 / 2007$.

69 JCC no. 142/1993. 
principio de jerarquía ha sido ampliamente rechazado por el Tribunal Constitucional húngaro ${ }^{70}$. En su lugar, la revisión constitucional de las leyes cualificadas se ha basado en la distribución competencial. Pero las leyes cualificadas se encuadran inequívocamente como un marco constitucional separado en el mismo nivel las leyes ordinarias, siguiendo el principio de jerarquía. Una ley cualificada no puede ser enmendada por una ley ordinaria, y una ley ordinaria no puede regular materias cualificadas $^{71}$. Con el marco constitucional anterior, el Tribunal ha conceptualizado el término «contenido esencial» de las leyes cardinales en aras de delimitar el ámbito de acción de las leyes ordinarias y cualificadas ${ }^{72}$. Sea como fuere, eran pocas las normas que contenía previsiones cardinales y ordinarias ${ }^{73}$.

Tal y como he señalado anteriormente, la Ley Fundamental reconsidera en algunos aspectos la exigencia legal de los dos tercios. Las cláusulas cardinales dan una lista explícita de las previsiones cardinales, por lo que existe la posibilidad de saber si estamos ante provisiones ordinarias u orgánicas. Las cláusulas cardinales pueden ser recurridas ante el Tribunal Constitucional ${ }^{74}$. Aunque los esfuerzos legislativos para que esa lista sea exhaustiva, es necesario seguir manteniendo el control de constitucionalidad ${ }^{75}$. Además, Hungría tiene varios modelos de leyes cualificadas: las «pequeñas de mayoría de dos tercios» es la forma general, pero para la limitación de la soberanía del Estado se exige la «amplia mayoría de dos tercios», aunque entre ambas no media relación jerárquica ${ }^{76}$. Otro cambio no menor es que la Ley Fundamental provee explícitamente el principio de competencia para diferenciar entre los dominios ordinarios y cardinales ${ }^{77}$. En consecuencia, el Tribunal Constitucional ha reconocido que una ley cualificada no puede contradecir una ley ordinaria anterior ${ }^{78}$.

Las anteriores consideraciones pueden asimilarse a las españolas: las leyes orgánicas están establecidas como fuente del Derecho en la propia Constitución, y en la propia norma que regula la organización y funcionamiento del Tribunal Constitucional ${ }^{79}$. A resultas de ello, las leyes orgánicas españolas están sometidas al control de constitucionalidad ${ }^{80}$. Aunque existen ciertos elementos jerárquicos

70 P. CSERNE - A. JAKAB, «A kétharmados törvények helye a magyar jogforrási hierarchiában», Fundamentum, 2001./2, works.bepress.com/peter_cserne/25, p. 42. pp. 40-47.

71 Decisión Nr. 4/1993. (II.12.) AB, ABH 1993, 48.; decisión Nr. 53/1995. (IX. 15.) AB, ABH 1995, 238.; decisión Nr. 3/1997. (I. 22.) AB, ABH 1997, 33.

72 Decisión Nr. 1/1999. (II. 24.) AB, ABH 1999, 25.

73 Cserne, 2015, p. 44.

74 Por ejemplo: act. XXXIV/1994 de la Ley Policial

75 BARNA 2013.

76 M. NÉmETH, «Sarkalatos dilemmák,» Ars boni legal review, 2015, www.arsboni.hu.

77 Decisión Nr. 1260/B/1997. AB, ABH 1998, 816.

78 Art. T) (1) de la Ley Fundamental de Hungría; decisión Nr. 43/2012. (XII. 20.) AB, ABH 2012, 296.

79 Art. 9. (3) de la Constitución Española; y art. 27. (2), art. 28. (2) de la Ley Orgánica del Tribunal Constitucional.

80 Troper 2012, p. 344 
entre la ley ordinaria y la orgánica ${ }^{81}$, la relación que media en líneas generales es el principio de competencia, sin que pueda considerarse que la ley orgánica es una categoría constitucional separada ${ }^{82}$. Aun es más, las leyes orgánicas integran el control de constitucionalidad de las normas legales ordinarias - el llamado bloque de constitucionalidad- ${ }^{83}$. Aunque se ha rechazado expresamente que estemos ante leyes con rango constitucional ${ }^{84}$, y por tanto deben cumplir con las exigencias constitucionales a la hora de dictarse ${ }^{85}$. El enfoque español es claramente pragmático: la ley orgánica tiene un ámbito de actuación definido, basado en una serie de materias legislativas ${ }^{86}$. Por ello la diferencia no es tan acusada como en Francia. Aun así, la intervención en el ámbito ordinario se frena por la intervención del Tribunal Constitucional, que anula tanto unas como otras si vulneran el sistema de competencias diseñado en la Constitución ${ }^{87}$. Como se incorporan al bloque de constitucionalidad, son fuentes infra-constitucionales, situándose a caballo entre el nivel constitucional y el nivel legal ordinario ${ }^{88}$.

Todos los modelos de leyes cualificadas contienen la exigencia de una mayoría cualificada, normalmente entre dos tercios y mayoría absoluta ${ }^{89}$. Debe diferenciarse claramente cada grupo, cada mayoría, siendo preferible la segunda, por no suponer un factor de riesgo del marco democrático y por ser más adaptable a la lógica parlamentaria. En caso de una mayoría estable que apoye al gobierno, la mayoría absoluta no modificará radicalmente la separación de poderes entre gobierno y oposición. El gobierno podrá hacer prevalecer sus deseos más allá de desacuerdos puntuales con la oposición. El papel a desempeñar por la mayoría absoluta, o el voto adicional al final del proceso $^{90}$, se ocupan de lo mismo: vigilar y controlar el poder de la mayoría. Con la ayuda de este umbral mínimo se consigue cierta estabilidad estructural, al menos de ciertas leyes. Aun es más, la oposición tendrá una buena oportunidad de hacer reflexionar al gobierno, reflexión que incluso puede provenir de sus propios diputados, en aras de retirar el proyecto $^{91}$. Desde que buena parte de los gobiernos son de coalición, los pequeños grupos que apoyen al gobierno pueden tener un papel decisivo, dado que se

81 Troper 2012, pp. 344-345.

82 JCC no. 236/2007.

83 Troper 2012, pp. 344-345.

84 L. Prakke - C. Kortmann - H. van den Brandhof, Constitutional law of 15 EU member states, 6th Edition, Kluwer, 2004, pp. 743.

85 JCC. no 53/ 1985.; JCC no. 101/1991.

86 Garcia Roca, F. J., «La 'decostruzione’ della Legge del Parlamento», E. Giancarlo - Ceccherini, (ed.), Profili di Diritto Parlamentare in Italia e in Spagna, Giappichelli, Torino, 1997, p. 142.

87 JCC No. 236/2007.

88 Troper, 2012, p. 346; M. Barceló i Serramalera, La ley Orgánica, ámbito material y posición en el sistema de fuentes, Atelier, Barcelona, 2004, pp. 30-31.

89 A los efectos del presente estudio, cuando se hable de mayoría absoluta se está hablando del apoyo de la mayoría de los Miembros.

90 Art. 81 (1) de la Constitución Española.

$91 \mathrm{Cc}, \mathrm{n}^{\circ} 2007-559$ DC du 6 decembre 2007. 
necesitan sus votos para alcanzar la mayoría absoluta ${ }^{92}$. Las leyes cualificadas no son un instrumento crucial, empleando los partidos los métodos tradicionales de obstrucción parlamentaria ${ }^{93}$. Esta aseveración también resulta válida para las Cámaras altas (segundas Cámaras) ${ }^{94}$.

Como consecuencia añadida, los gobiernos en minoría desaparecen en estos sistemas de mayorías absolutas. Y en el caso de consentimientos más exigentes — el de dos tercios — no solo la minoría gubernamental, sino gobiernos con posición mayoritaria no está capacitado para sacar adelante, en solitario, leyes cualificadas. En suma, en buena parte de situaciones de este tipo se exige el concurso de apoyos adicionales de la oposición. Esto explicaría a su vez el motivo por el que los gobiernos en minoría no son parte de la vida real en los países que siguen la versión de la mayoría absoluta.

Volviendo a la versión más exigente de la mayoría cualificada (la de dos tercios) desde la óptica de la separación de poderes en Hungría95, lo cierto es que esta no suele exigirse más que en países concretos de África y Latinoamérica ${ }^{96}$. Ello impide que el gobierno enmiende leyes cualificadas unilateralmente (salvo que cuente con el apoyo de esos dos tercios, claro está). Un gobierno con mayoría simple está obligado a negociar, al menos a cooperar, con la oposición, para alcanzar acuerdos. Las reglas que regulan los derechos y derechos de los parlamentarios no se han modificado en veinte años, precisamente porque no se alcanzan tales acuerdos ${ }^{97}$.

Esto implica que la oposición tiene un impacto directo en la regulación de algunas materias, no pudiendo identificarse el gobierno con el legislador. Como consecuencia, por un lado, la oposición controla directamente al gobierno y más eficazmente, quedando los intereses de las minorías mejor protegidos, al menos en lo que hace a la legislación cualificada ${ }^{98}$. Por otro, cuando escasea la cultura política y el deseo de cooperar, la oposición puede abusar de sus derechos, bloqueando todos intentos gubernamentales de modificar dicha legislación. Aun es más, en el ámbito de la ley ordinaria, el gobierno es responsable de las leyes aprobadas, pero una ley cualificada también es apoyada desde sectores no gubernamentales, por diputados de la oposición, por lo que la responsabilidad por esa legislación se difumina, rompiendo la lógica básica del parlamentarismo ${ }^{99}$.

92 P. Avril, Ecrits de théorie constitutionnelle et de droit politique, Éditions Université Panthéon Assas, Paris, 2010, p. 267.

93 J. Arlettaz - J. Bonnet, Pouvoirs et démocratie en France, Montpellier, CRDP, 2012, p. 211.

94 Avril 2014, p. 292.

95 Art. T) de la Ley Fundamental de Hungría.

96 Art. 63 de la Constitución de Chile; art. 112 de la Constitución la República Dominicana; art. 71. de la Constitución de Costa de Marfil [08.11.2016]; art. 83. de la Constitución de Guinea; art. 73. (3) y 84. (2) point b) de la Constitución de Islas de Islas Verdes.

97 A. Antal - I. Braun - L. Finta - Z. Töröк, Sarkalatos kérdések Méltányosság Politikaelemzö Központ, 24. 11. 2011, p. 20.

www.meltanyossag.hu/files/meltany/imce/doc/kp_sarkalatos_kerdesek_111122.pdf.

98 KiLÉNYI 1994, p. 208.

99 Decisión Nr. 55/2010. (V. 5.) AB, ABH 2010, 366. 
Cuando el gobierno tiene los dos tercios garantizados, la supermayoría exigida excluye a la oposición, que queda sin poder influir en las decisiones. El gobierno legislaría solo, sin criterios en contra, y las eventuales enmiendas a las leyes cualificadas reflejarían solo las preferencias gubernamentales. Posteriormente sería muy complicado revocar o modificar aquéllas. En una situación así el gobierno que tenga la mayoría de dos tercios garantizada puede aprobar la legislación que estime y que, a su vez, será vinculante a futuros gobiernos, con el consabido restringido margen de actuación. Esto es lo que se llama la dimensión temporal de la separación de poderes ${ }^{100}$. Esto no son meras disquisiciones teóricas: en Hungría, desde la transición democrática, el gobierno ha obtenido tres veces la mayoría parlamentaria de dos tercios en las elecciones legislativas. La versión estricta de la mayoría cualificada también nos ilustra sobre el rol de la democracia directa, en tanto que la legislación cualificada puede ser sometida a referéndum ${ }^{101}$.

\section{CONCLUSIONES}

La mayoría de dos tercios en el marco de la legislación cualificada puede distorsionar fácilmente las relaciones gobierno-oposición, bien otorgando demasiado poder a la oposición, bien pudiendo llegar a eliminar a largo plazo la influencia de esta en el proceso político. Desde esta óptica, el modelo de mayoría absoluta con controles adicionales es más compatible con la noción tradicional de la separación de poderes, mientras que el de la mayoría de dos tercios comporta más riesgos. Esto podría explicar la explicación estructural de la actual tendencia político-constitucional en Hungría: en manos de una fuerte mayoría parlamentaria, un amplio consenso operaría como un instrumento concreto de las políticas gubernamentales a largo plazo. Como consecuencia, la legislación aprobada por dos tercios de la mayoría debe ser eliminada del diseño constitucional, o al reducir menos su amplia extensión.

TITLE: Could qualified law undermine democracy? Case study from Hungary.

AвSTRACT: This study focuses on the so-called "cardinal laws» in Hungary: my primary purpose is to provide a better understanding of this concept, and especially to conceptualize the bistorical role and function of this legal framework in Hungary, during the democratic transition, and even nowadays. Particular highlight will be given to the special impact of cardinal laws under qualified parliamentary majority.

During the last decades, several countries have entrenched a special subcategory of law, which is adopted by stricter procedural rules, than the requirements of the ordinary legislative process. These laws are enacted by

100 SZEnTGÁli-Tóth 2014.

101 NÉMETH, 2015. 
qualified majority, by the consent of the two chambers of the legislation, they are subject to mandatory constitutional review before their promulgation, or additional safeguards are implemented in the ordinary legislative process. After having defined qualified law, and having provided a brief international overview, and outlined some further introductory considerations, I would focus on three aspects in Hungary: the historical background, the scope of qualified law, and the legal character of these norms. Under each point, the Hungarian development would be compared to the Spanish experience to demonstrate, why could be cardinal laws considered as a risk factor for democracy, and why this approach is not relevant as regard Spanish organic laws.

Resumen: Este estudio se centra en las llamadas Leyes Cardinales en Hungría. El principal objetivo es entender mejor el concepto, especialmente su rol bistórico y su funcionamiento dentro del ordenamiento del país, a lo largo de la transición a la democracia, y en la actualidad. Se destacará la importancia de este tipo de normas cuando existe una mayoría parlamentaria cualificada. A lo largo de las últimas décadas diversos países han adoptado una subcategoría especial de Ley, para cuya aprobación se exigen normalmente reglas procedimentales más estrictas que para las ordinarias, y que suelen exigir mayorías cualificadas, aprobándose por las dos Cámaras Legislativas, y sujetas a revisión constitucional previa, antes de su entrada en vigor. En general, gozan de exigencias mayores y de controles más severos que las leyes ordinarias. Después de definir la noción, y de hacer un breve repaso por la escena internacional así como por otras cuestiones introductorias, se centra la atención en tres aspectos: el bagaje histórico que presentan, las materias que regulan, y los caracteres que más destacan. En cada uno de ellos se comparará el caso húngaro con el caso español para demostrar cómo las Leyes Cardinales pueden ser consideradas un factor de riesgo para la democracia, y por qué no sucede lo mismo para el caso de España.

KeY wORDs: Organic Law, Cardinal Law, Qualified Majority, Laws with constitutional force, Laws adopted by two-thirds majority.

Palabras Clave: Ley Orgánica, Ley Cardinal, Mayoría Cualificada, Normas con rango constitucional, Normas aprobadas por dos tercios de la mayoría.

FECHA DE RECEPCIÓN: 17.12.2017 FECHA DE ACEPTACIÓN: 01.02.2018 
